\title{
Validación de una investigación usando la estadística como herramienta
}

\section{Research validation using statistics as tool}

Gabriel Julio ${ }^{1 *}$

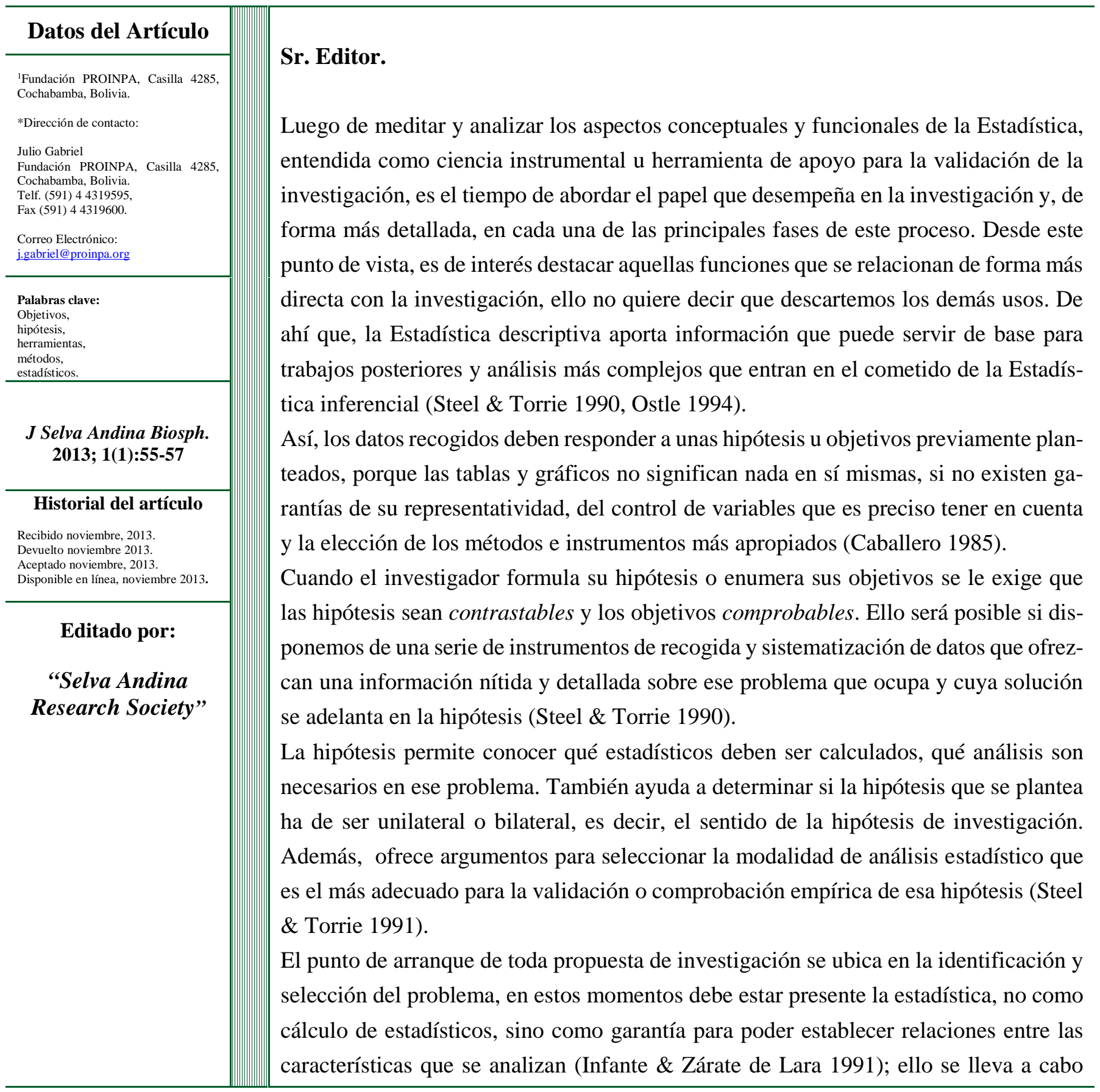




\begin{tabular}{|c|}
\hline $\begin{array}{l}\text { mediante diversos modelos estadísticos, desde ellos se busca si existe alguno que per- } \\
\text { mita la resolución del problema o bien, si se pudieran aplicar varios, seleccionar aquél } \\
\text { que es más adecuado en función de unos criterios fijados (Ostle 1994). } \\
\text { Así, cuando se procede a analizar el problema y sus características identificativas se } \\
\text { pondrán de manifiesto las variables que intervienen en esos procesos, cómo actúan en } \\
\text { el contexto de la investigación, qué datos de la variable dependiente necesitan ser re- } \\
\text { cogidos, qué calidad tiene la información, qué pruebas estadísticas es preciso aplicar, } \\
\text { en suma se trata de identificar si existe un modelo estadístico capaz de ofrecer una } \\
\text { respuesta adecuada a ese problema (Uriel \& Aldías 2005). } \\
\text { Si el investigador no contempla estas sugerencias se puede encontrar más adelante con } \\
\text { un camino sin salida, donde no puede avanzar más y, en ocasiones, se puede ver obli- } \\
\text { gado a abandonar el trabajo. A veces se sigue adelante, pero a riesgo de alcanzar unos } \\
\text { resultados que no pueden ser considerados válidos, por su incoherencia entre el pro- } \\
\text { blema y el modelo estadístico generado para su resolución, pues muchos lo utilizan } \\
\text { como una muletilla. } \\
\text { En síntesis, se puede afirmar que es la estadística la que permitirá asegurar que el pro- } \\
\text { blema cumple una condición inexcusable en su formulación que sea resoluble, es decir, } \\
\text { que con los datos que se puedan recoger en un futuro sea posible alcanzar las respuestas } \\
\text { esperadas. } \\
\text { De lo mencionado, se podría indicar que la Estadística es un conjunto de técnicas para } \\
\text { la colección, manejo, descripción y análisis de información, de manera que las conclu- } \\
\text { siones obtenidas de ella tengan un grado de confiabilidad especificado (Infante \& Zá- } \\
\text { rate de Lara 1991). Sin embargo, la ciencia estadística suministra una base objetiva } \\
\text { para el análisis de problemas en los que los datos se apartan de la causalidad exacta } \\
\text { (Litle \& Hills 1991), lo cual le caracteriza como una herramienta de gran utilidad en } \\
\text { la validación de una investigación. }\end{array}$ \\
\hline
\end{tabular}

\section{Conflictos de interés}

El presente trabajo no genera conflictos de interés

\section{Literatura citada}

Caballero W Introducción a la Estadística. IICA, San José, Costa Rica. 1985; 289 pp.
Infante S, Zárate de Lara GP Métodos estadísticos, un enfoque interdisciplinario. Trillas, México D.F., México. 1991; 643 pp.

Liltle TM, Hills FJ Métodos estadísticos para la investigación en la agricultura. Trad. del inglés por María Isabel Silveira y Roberto 
A Flores. Trillas, México D.F., México. 1990; 270 pp.

Ostle B Estadística aplicada: Técnicas de la estadística moderna, cuándo y dónde aplicarlas. Limusa, México D.F., México. 1994; $629 \mathrm{pp}$.

Steel RGD, Torrie JH Bioestadística: principios y procedimientos. Trad. del inglés por
Ricardo Marínez, 2da.ed. McGraw-Hill, México D.F., México. 1990; 622 pp.

Uriel E, Aldías J Análisis multivariante apli cado. Thompson, Madrid, España. 2005; $531 \mathrm{pp}$. 